\title{
Pharmacogenetic determinants of outcomes on triplet hepatic artery infusion and intravenous cetuximab for liver metastases from colorectal cancer (European trial OPTILIV, NCT00852228)
}

Francis Lévi ${ }^{\star}, 1,2,3,4$, Abdoulaye Karaboué ${ }^{1,5}$, Raphaël Saffroy ${ }^{1,2,3}$, Christophe Desterke ${ }^{1,2}$, Valerie Boige ${ }^{6}$, Denis Smith ${ }^{7}$, Mohamed Hebbar ${ }^{8}$, Pasquale Innominato ${ }^{1,4}$, Julien Taieb ${ }^{9}$, Carlos Carvalho ${ }^{10}$, Rosine Guimbaud ${ }^{11}$, Christian Focan ${ }^{12}$, Mohamed Bouchahda ${ }^{1,3,13}$, René Adam ${ }^{1,2,3}$, Michel Ducreux ${ }^{6}$, Gérard Milano ${ }^{14}$ and Antoinette Lemoine ${ }^{1,2,3}$ on behalf of ARTBC International

'INSERM, UMRS 935 Team 'Cancer Chronotherapy and Postoperative Liver Function', Campus CNRS, 7 rue Guy Môquet, and UMRS 1193 'Physiopathology and treatment of Liver diseases', Paul Brousse Hospital, 14 avenue Paul-Vaillant-Couturier, 94800 Villejuif, France; ${ }^{2}$ Université Paris Sud, UFR médecine, Institut André Lwoff, Paul Brousse Hospital, 14 avenue Paul-Vaillant-Couturier, 94800 Villejuif, France; ${ }^{3}$ Assistance Publique-Hopitaux de Paris, Paul Brousse Hospital, Departments of Medical Oncology, Biochemistry and Oncogenetics, and Hepatobiliary Center, 14 avenue Paul-Vaillant-Couturier, 94800 Villejuif, France; ${ }^{4}$ Cancer Chronotherapy Unit, Warwick Medical School, Warwick University, Gibbet Hill Road, Coventry CV4 7AL, UK; ${ }^{5}$ AK-SCIENCE, Research and Therapeutic Innovation, 34 Boulevard de Stalingrad, 94400 Vitry-Sur-Seine, France; ${ }^{6}$ Gustave-Roussy Institute, 114 Rue Edouard Vaillant, 94400 Villejuif, France; ${ }^{7}$ Saint André Hospital, 1 Rue Jean Burguet, 33000 Bordeaux, France; ${ }^{8}$ Medical Oncology Unit, Huriez Hospital, 1 rue Polonovski, 59037 Lille, France; ${ }^{9}$ Georges Pompidou European Hospital, 20 Rue Leblanc, 75015 Paris, France; ${ }^{10}$ Champalimaud Clinical Centre, Medical Oncology Department, Avenida Brasília, 1400-038 Lisbon, Portugal; ${ }^{11}$ Digestive Medical Oncology Unit, Toulouse University Hospital, 170 avenue de Casselardit, 31059 Toulouse, France; ${ }^{12} \mathrm{CHC}$ Saint Joseph Clinics, rue de Hesbaye 75 , 4000 Liège, Belgium; ${ }^{13}$ Ramsay GDS Mousseau Clinics, 2 Avenue de Mousseau, 91035 Evry, France and ${ }^{14}$ Oncopharmacology Laboratory, EA 3836, Antoine Lacassagne Center, 33, Avenue de Valombrose, 06189 Nice, France

Background: The hepatic artery infusion (HAl) of irinotecan, oxaliplatin and 5-fluorouracil with intravenous cetuximab achieved outstanding efficacy in previously treated patients with initially unresectable liver metastases from colorectal cancer. This planned study aimed at the identification of pharmacogenetic predictors of outcomes.

Methods: Circulating mononuclear cells were analysed for 207 single-nucleotide polymorphisms (SNPs) from 34 pharmacology genes. Singlenucleotide polymorphisms passing stringent Hardy-Weinberg equilibrium test were tested for their association with outcomes in 52 patients (male/female, 36/16; WHO PS, 0-1).

Results: VKORC1 SNPs (rs9923231 and rs9934438) were associated with early and objective responses, and survival. For rs9923231, T/T achieved more early responses than $\mathrm{C} / \mathrm{T}(50 \%$ vs $5 \%, P=0.029)$ and greatest 4 -year survival $(46 \%$ vs $0 \%, P=0.006)$. N-acetyltransferase-2 (rs 1041983 and rs 1801280) were associated with up to seven-fold more macroscopically complete hepatectomies. Progression-free survival was largest in $A B C B 1$ rs $1045642 \mathrm{~T} / \mathrm{T}(P=0.026)$ and $\mathrm{rs} 2032582 \mathrm{~T} / \mathrm{T}(P=0.035)$. Associations were found between toxicities and gene variants $(P<0.05)$, including neutropenia with ABCB1 (rs1045642) and SLCOB3 (rs4149117 and rs7311358); and diarrhoea with CYP2C9 (rs1057910), CYP2C19 (rs3758581), UGT1A6 (rs4124874) and SLC22A1 (rs72552763).

Conclusions: VKORC1, NAT2 and ABCB1 variants predicted for HAl efficacy. Pharmacogenetics could guide the personalisation of liver-targeted medico-surgical therapies.

*Correspondence: Professor F Lévi; E-mail: F.Levi@warwick.ac.uk

Received 15 May 2017; revised 18 July 2017; accepted 24 July 2017; published online 17 August 2017

(C) 2017 Cancer Research UK. All rights reserved 0007-0920/17 
The determination of non-invasive biomarkers has long been advocated for improving efficacy or reducing toxicity through helping personalise both drug selection and dose determination in cancer chemotherapy protocols (Hertz and Rae, 2015). Thus, allele frequencies of genes responsible for anticancer drug absorption, distribution, metabolism and elimination (ADME) have been related to pharmacokinetics, toxicities or response (Hertz and Rae, 2015). Classical examples of single-nucleotide polymorphisms (SNPs) associated with individual toxicities of an anticancer drug include genes UDP-glucuronosyltransferase 1A (UGT1A) for irinotecan, and thymidylate synthase and DPYD for fluoropyrimidines (Falvella et al, 2015; Hertz and Rae, 2015; Milano, 2016). However, cancer chemotherapy usually combines several anticancer drugs. As an example, hepatic artery infusion (HAI) of irinotecan, 5-fluorouracil (F) and oxaliplatin (O) (IFO) was recently combined with intravenous cetuximab in previously treated patients with liver metastases from colorectal cancer (LM-CRC) within European Phase II clinical trial OPTILIV (Levi et al, 2016). The conversion rate of previously unresectable LM to curative intent hepatectomy (R0-R1) reached 30\%, and overall median survival was 25 months despite protocol application as median third-line chemotherapy (Bouchahda et al, 2016; Levi et al, 2016). Achieving early rather than late tumour shrinkage has indeed become an important goal of chemotherapy of LM-CRC, as it can translate into previously unforeseen surgical resections with prolonged survival or cure (Bismuth et al, 1996; Giacchetti et al, 1999; Adam et al, 2004). Hence, we used a multiple molecular typing method, using the iPLEX Agena Bioscience MassARRAY platform (Williams et al, 2008), in order to identify a possible genetic basis for the efficacy and toxicities of triplet HAI and i.v. cetuximab. No pharmacogenetic study has yet explored such issue for HAI drugs despite its original mechanisms of action involving the direct metastases exposure to anticancer drugs (Kemeny et al, 2006; Bouchahda et al, 2011; D’Angelica et al, 2015; Maeda et al, 2016).

\section{PATIENTS AND METHODS}

The pharmacogenetic assessment in OPTILIV was approved by the ethical committee and the national regulatory authorities in four countries. It aimed at the identification of those constitutive SNPs that would predict for success in main outcomes on OPTILIV protocol treatment.

Patients. Participants in OPTILIV protocol had a histological proof of colorectal cancer, unresectable liver metastases, wild-type KRAS tumour, WHO performance status of $0-1$ and adequate biology (Levi et al, 2016). They had received one, two or three prior chemotherapy protocols. They signed informed consent for the pharmacogenetic assessment (Levi et al, 2016).

Treatment. All patients received OPTILIV protocol treatment consisting in biweekly administration of hepatic artery infusion of IFO, combined to intravenous infusion of cetuximab. Hepatic artery infusion was administered either as a conventional modality or according to chronomodulated delivery, according to institution experience (Bouchahda et al, 2016; Levi et al, 2016).

Treatment evaluation. Blood cell counts, serum chemistries and adverse events were monitored before each treatment course and graded according to NCI-CTCAE vs3.0 criteria. Tumour response imaging was obtained every three courses and classified according to RECIST. Patients were assessed for secondary liver surgery at iterative oncosurgical evaluations after three, six or nine cycles (Bouchahda et al, 2016).

Pharmacogenetics. A volume of $10 \mathrm{ml}$ of whole blood was drawn in an EDTA-tube before treatment onset (between 0800 and 1000 hours) and stored at $-20{ }^{\circ} \mathrm{C}$. Sampling was occasionally performed at other times for technical reason. Genomic DNA was extracted from blood using a QIAamp DNA mini kit (Qiagen, Courtaboeuf, France). The concentration and purity of the DNA were determined by absorbance at 260 and $280 \mathrm{~nm}$ using a Nanovue spectrophotometer (Biochrom, Harvard Bioscience Inc, Holliston, MA, USA). The genotyping to investigate biomarkers associated with drug ADME was performed on the Sequenom Massarray platform (Sequenom, San Diego, CA, USA). The iPLEX ADME PGx panel (Sequenom) screening for 207 polymorphisms in 34 genes and 200 assays developed for screening of known, high-value target genes associated with drug metabolism and toxicity was used with Typer Assay designer software (Agena Bioscience GmbH, Hamburg, Germany) and iPLEX Gold biochemistry (Agena Bioscience $\mathrm{GmbH}$ ). The PCR primers and the extension primers were mixed in eight unique pools, and used for amplification of target regions and interrogation of the specific base composition at the target site using single base extension.

Multiplexed PCR was performed in $5 \mu \mathrm{l}$ volumes after DNA dilution. The amplification protocol comprised an initial incubation at $94^{\circ} \mathrm{C}$ for $4 \mathrm{~min}$; 45 cycles of denaturation at $95^{\circ} \mathrm{C}$ for $20 \mathrm{~s}$, annealing at $62{ }^{\circ} \mathrm{C}$ for $30 \mathrm{~s}$ and extension at $72^{\circ} \mathrm{C}$ for $1 \mathrm{~min}$; and final incubation at $72^{\circ} \mathrm{C}$ for $3 \mathrm{~min}$. Unincorporated deoxynucleoside triphosphates were dephosphorylated by the addition of $2 \mu \mathrm{l}$ of premix including $0.3 \mathrm{U}$ of shrimp alkaline phosphatase (Sequenom). The reaction mixture was incubated at $37^{\circ} \mathrm{C}$ for $40 \mathrm{~min}$, after which the phosphatase was inactivated by incubation for $5 \mathrm{~min}$ at $85^{\circ} \mathrm{C}$. Final primer extension was carried out using primer extension probes, the appropriate $\mathrm{dNTP} / \mathrm{ddNTP}$ combination and 0.5 units of Thermosequenase DNA polymerase (Sigma-Aldrich Chimie Sarl, Lyon, France). Reactions were cycled at $94^{\circ} \mathrm{C}$ for $2 \mathrm{~min}$, followed by 40 cycles of $94^{\circ} \mathrm{C}$ for $5 \mathrm{~s}$ and 5 cycles of $52^{\circ} \mathrm{C}$ for $5 \mathrm{~s}$ and $80^{\circ} \mathrm{C}$ for $5 \mathrm{~s}$, and final incubation at $72^{\circ} \mathrm{C}$ for $3 \mathrm{~min}$. After addition of a cation exchange resin to remove residual salt form the reactions, $7 \mathrm{nl}$ of the purified primer extension reaction was loaded onto a matrix pad of a spectroCHIP (Sequenom). SpectroCHIPs were analysed using MALDI-TOF mass spectrometer.

Pharmacokinetics. Circulating drug and main metabolite levels were determined following iterative blood sampling during the first treatment course of 11 patients on chronomodulated HAI. The serum or plasma concentrations of cetuximab, irinotecan, SN38, total and ultrafiltrated oxaliplatin, and 5-fluorouracil were determined according to Levi et al (2017).

Statistical considerations. The association of gene polymorphisms with toxicity and efficacy was first assessed using adequate non-parametric tests (Mann-Whitney $U$-test, Fisher exact test or Kruskal-Wallis). A $P$-value of $<0.05$ was considered as statistically significant. Statistical analyses were performed using SPSS for Windows version 18.0 (SPSS Inc., Chicago, IL, USA).

Genotypic data analysis. Genomic coordinates of polymorphisms were annotated on GRCh37.p13 version of the human genome. Genotypic data obtained with the Sequenom technology have been formatted to form a compatible matrix with the software SNPAnalyzer (Yoo et al, 2008). Preprocessing of data was performed by removing samples with $>50 \%$ missing genotype; removing also SNPs with missing genotypes over $10 \%$ and SNPs with minor allele frequency $<5 \%$. This preprocessing analysis also included a Hardy-Weinberg equilibrium (HWE) test: SNPs with HWE $P$-value $<0.05$ were withdrawn from further analysis. Genetic association was validated using Fisher exact test with Bonferroni's multitesting corrections for controlling for false discovery rate. Analysis of linkage disequilibrium 
Table 1. Main characteristics of all 52 patients and according to early response and complete macroscopic liver resection

Early response $(n=49)^{a}$

Liver resection $(n=52)$

\begin{tabular}{|c|c|c|c|c|c|c|c|}
\hline Patient characteristics & All $(N=52)$ & Yes $(n=11)$ & No $(n=38)$ & $P$ & R0-R1 $(n=14)$ & No resection $(n=38)$ & $P$ \\
\hline \multicolumn{8}{|l|}{ Age (years) } \\
\hline Median (range) & $59(33-76)$ & $57(33-76)$ & $60(40-73)$ & 0.310 & $49(33-76)$ & $60(48-75)$ & 0.003 \\
\hline \multicolumn{8}{|l|}{ Sex } \\
\hline $\begin{array}{l}\text { Male } \\
\text { Female }\end{array}$ & $\begin{array}{l}36(69.2 \%) \\
16(30.8 \%)\end{array}$ & $\begin{array}{l}6(18.2 \%) \\
5(31.3 \%)\end{array}$ & $\begin{array}{l}27(81.8 \%) \\
11(68.8 \%)\end{array}$ & 0.466 & $\begin{array}{r}29(80.6 \%) \\
9(56.3 \%)\end{array}$ & $\begin{array}{l}7(19.4 \%) \\
7(43.8 \%)\end{array}$ & 0.094 \\
\hline \multicolumn{8}{|l|}{ Site of primary tumour } \\
\hline \multicolumn{8}{|c|}{ No. of chemotherapy lines } \\
\hline $\begin{array}{l}1 \\
2-3\end{array}$ & $\begin{array}{l}21(40.4 \%) \\
31(59.6 \%)\end{array}$ & $\begin{array}{l}5(27.8 \%) \\
6(19.4 \%)\end{array}$ & $\begin{array}{l}13(72.2 \%) \\
25(80.6 \%)\end{array}$ & 0.503 & $\begin{array}{r}10(47.6 \%) \\
4(12.9 \%)\end{array}$ & $\begin{array}{l}11(52.4 \%) \\
27(87.1 \%)\end{array}$ & 0.006 \\
\hline \multicolumn{8}{|c|}{ WHO performance status } \\
\hline $\begin{array}{l}\text { WHO PS } 0 \\
\text { WHO PS } 1 / 2\end{array}$ & $\begin{array}{l}31(59.6 \%) \\
21(40.4 \%)\end{array}$ & $\begin{array}{l}7(24.1 \%) \\
4(20.0 \%)\end{array}$ & $\begin{array}{l}22(75.9 \%) \\
16(80.0 \%)\end{array}$ & 1 & $\begin{array}{l}8(25.8 \%) \\
6(28.6 \%)\end{array}$ & $\begin{array}{l}23(74.2 \%) \\
15(71.4 \%)\end{array}$ & 0.825 \\
\hline \multicolumn{8}{|c|}{ Metastases location in liver } \\
\hline $\begin{array}{l}\text { Unilateral } \\
\text { Bilateral }\end{array}$ & $\begin{array}{r}9(17.3 \%) \\
43(82.7 \%)\end{array}$ & $\begin{array}{l}2(25.0 \%) \\
9(22.0 \%)\end{array}$ & $\begin{array}{r}6(75.0 \%) \\
32(78.0 \%)\end{array}$ & 1 & $\begin{array}{r}4(44.4 \%) \\
10(23.3 \%)\end{array}$ & $\begin{array}{r}5(55.6 \%) \\
33(76.7 \%)\end{array}$ & 0.229 \\
\hline \multicolumn{8}{|l|}{ Liver involvement } \\
\hline $\begin{array}{l}\leqslant 25 \% \\
>25 \%\end{array}$ & $\begin{array}{l}21(40.4 \%) \\
31(59,6 \%)\end{array}$ & $\begin{array}{l}5(25.0 \%) \\
6(20.7 \%)\end{array}$ & $\begin{array}{l}15(75.0 \%) \\
23(79.3 \%)\end{array}$ & 0.740 & $\begin{array}{l}9(42.9 \%) \\
5(16.1 \%)\end{array}$ & $\begin{array}{l}12(57.1 \%) \\
26(83.9 \%)\end{array}$ & 0.033 \\
\hline \multicolumn{8}{|l|}{ No. of liver metastases } \\
\hline Median (range) & $9(1-69)$ & $15(2-50)$ & $9(1-69)$ & 0.169 & $8(2-50)$ & $10(1-69)$ & 0.538 \\
\hline \multicolumn{8}{|c|}{ Largest meta diameter $(\mathrm{mm})$} \\
\hline Median (range) & $56.5(15-172)$ & $50(15-93)$ & $59(18-172)$ & 0.151 & $37(15-131)$ & $60(18-172)$ & 0.076 \\
\hline \multicolumn{8}{|c|}{ No. of liver segments involved } \\
\hline \multicolumn{8}{|c|}{$\begin{array}{l}\text { Abbreviations: } \mathrm{PS}=\text { performance status; } \mathrm{WHO}=\text { World Health Organisation. } \\
\mathrm{a}_{\text {Thee patients were not assessed for response. }} \\
{ }^{\mathrm{b}} \text { Colon, rectum, lung or lymph node. }\end{array}$} \\
\hline
\end{tabular}

(LD) was calculated by the $\mathrm{LD}$ index $\left|\mathrm{D}^{\prime}\right|$ and retained significant polymorphisms for Pearson's correlation coefficients $>0.80$. The LD analysis was performed using the method of Gabriel without any limit in genetic distance parameter (Gabriel et al, 2002).

Pharmacokinetics analyses. For each drug and for both metabolites, maximum plasma concentration (Cmax) values were determined, with their time to reach $C \max (t \max )$ values. Area under the concentration curves were calculated for each drug (Levi et al, 2017). The relations between these parameters and drug metabolism polymorphisms were statistically validated using analysis of variance.

\section{RESULTS}

Patient characteristics and outcomes. Fifty-two out of 64 patients (85\%) with unresectable LM-CRC enrolled into the OPTILIV trial consented for and had valid sample for the study (Table 1; Figure 1). All the patients had received one to three chemotherapy protocols before OPTILIV. The main dose-limiting grade 3-4 toxicities on OPTILIV were neutropenia ( $40.4 \%$ of the patients), fatigue $(21.2 \%)$ and diarrhea (17.3\%; Table 2). Twenty patients had an objective
64 pts registered

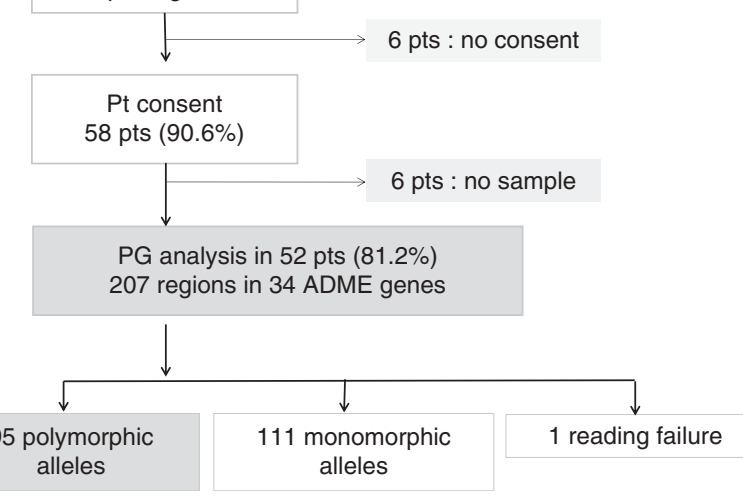

Figure 1. Consort diagram. This pharmacogenetic study involved 52 patients out of the 64 who had been registered in OPTILIV for receiving a combination of intravenous cetuximab and $\mathrm{HAl}$ of irinotecan, oxaliplatin and 5-fluorouracil (85\% of the trial population). Thirty-four drug metabolism genes were analysed for a total of 207 candidate SNPs. Ninety-five of them were polymorphic (49.7\%). Their association with clinical outcomes was investigated further. 
Table 2. Characteristics of patients according main grade 3-4 toxicities over the first six courses

\begin{tabular}{|c|c|c|c|c|c|c|c|c|c|c|c|c|c|}
\hline \multirow[b]{2}{*}{$\begin{array}{l}\text { Patient } \\
\text { characteristics }\end{array}$} & \multirow[b]{2}{*}{$\begin{array}{c}\text { All, } N=51 \\
(100 \%)\end{array}$} & \multicolumn{3}{|c|}{ Neutropenia (grade 3-4) } & \multicolumn{3}{|c|}{ Diarrhoea (grade 3-4) } & \multicolumn{3}{|c|}{ Fatigue (grade 3-4) } & \multicolumn{3}{|c|}{ Thrombosis (grade 3-4) } \\
\hline & & $\begin{array}{c}\text { Yes, } n=20 \\
(39.2 \%)\end{array}$ & $\begin{array}{c}\text { No, } n=31 \\
(60.8 \%)\end{array}$ & $P$ & $\begin{array}{c}\text { Yes, } n=9 \\
(17.6 \%)\end{array}$ & $\begin{array}{c}\text { No, } n=42 \\
(82.4 \%)\end{array}$ & $P$ & $\begin{array}{c}\text { Yes, } n=10 \\
(19.6 \%)\end{array}$ & $\begin{array}{c}\text { No, } n=41 \\
(80.4 \%)\end{array}$ & $P$ & $\begin{array}{c}\text { Yes, } n=2 \\
(3.9 \%)\end{array}$ & $\begin{array}{c}\text { No, } n=49 \\
(96.1 \%)\end{array}$ & $P$ \\
\hline \multicolumn{14}{|l|}{ Age (years) } \\
\hline Median (range) & $59(33-76)$ & $60(33-72)$ & $49(40-76)$ & 0.557 & $63(54-73)$ & $58(33-73)$ & 0.053 & $60(40-72)$ & $59(33-76)$ & 0.963 & $47(33-60)$ & $59(33-76)$ & 0.083 \\
\hline \multicolumn{14}{|l|}{ Sex } \\
\hline $\begin{array}{l}\text { Male } \\
\text { Female }\end{array}$ & $\begin{array}{l}35 \text { (68.6\%) } \\
16(31.4 \%)\end{array}$ & $\begin{array}{r}11(31.4 \%) \\
9(56.3 \%)\end{array}$ & $\begin{array}{r}24(68.6 \%) \\
7(43.8 \%)\end{array}$ & 0.092 & $\begin{array}{l}5 \text { (14.3\%) } \\
4(25.0 \%)\end{array}$ & $\begin{array}{l}30(85.7 \%) \\
12(75.0 \%)\end{array}$ & 0.436 & $\begin{array}{l}4(11.4 \%) \\
6(37.5 \%)\end{array}$ & $\begin{array}{l}31(88.6 \%) \\
10(62.5 \%)\end{array}$ & 0.054 & $\begin{array}{l}1(2.9 \%) \\
1(6.3 \%)\end{array}$ & $\begin{array}{l}34(97.1 \%) \\
15(93.8 \%)\end{array}$ & 0.533 \\
\hline \multicolumn{14}{|c|}{ Site of primary tumour } \\
\hline $\begin{array}{l}\text { Colon } \\
\text { Rectum }\end{array}$ & $\begin{array}{l}40(78.4 \%) \\
11(21.6 \%)\end{array}$ & $\begin{array}{r}18(45.0 \%) \\
2(18.2 \%)\end{array}$ & $\begin{array}{r}22(55.0 \%) \\
9(81.8 \%)\end{array}$ & 0.166 & $\begin{array}{l}6(15.0 \%) \\
3(27.3 \%)\end{array}$ & $\begin{array}{r}34(85.0 \%) \\
8(72.7 \%)\end{array}$ & 0.385 & $\begin{array}{l}9 \text { (22.5\%) } \\
1(9.1 \%)\end{array}$ & $\begin{array}{l}31(77.5 \%) \\
10(90.9 \%)\end{array}$ & 0.428 & $\begin{array}{l}2(5.0 \%) \\
0\end{array}$ & $\begin{array}{l}38(95.0 \%) \\
11(100 \%)\end{array}$ & 1 \\
\hline \multicolumn{14}{|c|}{ No. of chemotherapy lines } \\
\hline $\begin{array}{l}1 \\
2-3\end{array}$ & $\begin{array}{l}20(39.2 \%) \\
31(60.8 \%)\end{array}$ & $\begin{array}{c}8(40 \%) \\
12(38.7 \%)\end{array}$ & $\begin{array}{l}12(60.0 \%) \\
19(61.3 \%)\end{array}$ & 0.927 & $\begin{array}{l}2(10.0 \%) \\
7(22.6 \%)\end{array}$ & $\begin{array}{l}18(90.0 \%) \\
24(77.4 \%)\end{array}$ & 0.454 & $\begin{array}{l}3 \text { (15.\%) } \\
7 \text { (22.58\%) }\end{array}$ & $\begin{array}{l}17(85.0 \%) \\
24(77.4 \%)\end{array}$ & 1 & $\begin{array}{l}2(10.0 \%) \\
0\end{array}$ & $\begin{array}{l}18(90.0 \%) \\
31(100 \%)\end{array}$ & 0.149 \\
\hline \multicolumn{14}{|c|}{ WHO performance status } \\
\hline $\begin{array}{l}\text { WHO PS } 0 \\
\text { WHO PS } 1 / 2\end{array}$ & $\begin{array}{l}30(58.8 \%) \\
21(41.2 \%)\end{array}$ & $\begin{array}{r}12(40.0 \%) \\
8(38.1 \%)\end{array}$ & $\begin{array}{l}18(60.0 \%) \\
13(61.9 \%)\end{array}$ & 0.891 & $\begin{array}{l}6(20.0 \%) \\
3(14.3 \%)\end{array}$ & $\begin{array}{l}24(80.0 \%) \\
18(85.7 \%)\end{array}$ & 0.720 & $\begin{array}{l}6(20.0 \%) \\
4(19.0 \%)\end{array}$ & $\begin{array}{l}24(80.0 \%) \\
17(81.0 \%)\end{array}$ & 1 & $\begin{array}{l}1(3.3 \%) \\
1(4.8 \%)\end{array}$ & $\begin{array}{l}29(96.7 \%) \\
20(95.2 \%)\end{array}$ & 1 \\
\hline \multicolumn{14}{|c|}{ Synchronous metastases } \\
\hline $\begin{array}{l}\text { Yes } \\
\text { No }\end{array}$ & $\begin{array}{r}45(88.2 \%) \\
6(11.8 \%)\end{array}$ & $\begin{array}{r}16(35.6 \%) \\
4(66.7 \%)\end{array}$ & $\begin{array}{r}29(64.4 \%) \\
2(33.3 \%)\end{array}$ & 0.195 & $\begin{array}{l}7(16.6 \%) \\
2(33.3 \%)\end{array}$ & $\begin{array}{r}38(84.4 \%) \\
4(66.7 \%)\end{array}$ & 0.284 & $\begin{array}{l}9(20.0 \%) \\
1(16.7 \%)\end{array}$ & $\begin{array}{r}36(80.0 \%) \\
5(83.3 \%)\end{array}$ & 1 & $\begin{array}{l}2(4.4 \%) \\
0\end{array}$ & $\begin{array}{c}43(95.6 \%) \\
6(100 \%)\end{array}$ & 1 \\
\hline \multicolumn{14}{|c|}{ Metastases location in liver } \\
\hline $\begin{array}{l}\text { Unilateral } \\
\text { Bilateral }\end{array}$ & $\begin{array}{r}9(17.6 \%) \\
42(82.4 \%)\end{array}$ & $\begin{array}{r}2(22.2 \%) \\
18(42.9 \%)\end{array}$ & $\begin{array}{r}7(77.8 \%) \\
24(57.1 \%)\end{array}$ & 0.454 & $\begin{array}{l}2(22.2 \%) \\
7(16.7 \%)\end{array}$ & $\begin{array}{r}7(77.8 \%) \\
35(83.3 \%)\end{array}$ & 0.651 & $\begin{array}{l}3(33.3 \%) \\
7(16.7 \%)\end{array}$ & $\begin{array}{r}6(66.7 \%) \\
35(83.3 \%)\end{array}$ & 0.353 & $\begin{array}{l}0 \\
2(4.8 \%)\end{array}$ & $\begin{array}{c}9(100 \%) \\
40(95.2 \%)\end{array}$ & 1 \\
\hline \multicolumn{14}{|l|}{ Liver involvement } \\
\hline $\begin{array}{l}\leqslant 25 \% \\
>25 \%\end{array}$ & $\begin{array}{l}20(39.2 \%) \\
31(60.8 \%)\end{array}$ & $\begin{array}{r}9(45.0 \%) \\
11(35.5 \%)\end{array}$ & $\begin{array}{l}11(55.0 \%) \\
20(64.5 \%)\end{array}$ & 0.497 & $\begin{array}{l}3(15.0 \%) \\
6(19.4 \%)\end{array}$ & $\begin{array}{l}17 \text { (85.0\%) } \\
25(80.6 \%)\end{array}$ & 1 & $\begin{array}{l}7(35.0 \%) \\
3 \text { (9.7\%) }\end{array}$ & $\begin{array}{l}13(65.0 \%) \\
28(90.3 \%)\end{array}$ & 0.036 & $\begin{array}{l}1(5.0 \%) \\
1(3.2 \%)\end{array}$ & $\begin{array}{l}19(95.0 \%) \\
30(96.8 \%)\end{array}$ & 1 \\
\hline \multicolumn{14}{|c|}{ No. of liver metastases } \\
\hline Median (range) & $9(1-69)$ & $10(3-50)$ & $9(1-69)$ & 0.925 & $8(1-50)$ & $10(1-69)$ & 0.627 & $5(1-12)$ & $10(1-69)$ & 0.038 & $18(5-30)$ & $9(1-69)$ & 0.772 \\
\hline \multicolumn{14}{|c|}{ Largest meta diameter $(\mathrm{mm})$} \\
\hline Median (range) & $57(15-172)$ & $57(18-110)$ & $57(15-172)$ & 0.667 & $65(25-172)$ & $51(15-130)$ & 0.010 & $60(18-110)$ & $56(15-172)$ & 0.961 & 70 (39-101) & $57(15-172)$ & 0.694 \\
\hline \multicolumn{14}{|c|}{ No. of liver segments involved } \\
\hline Median (range) & $6(1-8)$ & $6(2-8)$ & $6(1-8)$ & 0.670 & $7(2-8)$ & $6(1-8)$ & 0.901 & $5(2-7)$ & $7(1-8)$ & 0.031 & $6(5-7)$ & $6(1-8)$ & 0.860 \\
\hline \multicolumn{14}{|l|}{ Sites involved } \\
\hline $\begin{array}{l}\text { Liver only } \\
\text { Liver + other sites }^{\text {a }}\end{array}$ & $\begin{array}{l}30(58.8 \%) \\
21(41.2 \%)\end{array}$ & $\begin{array}{r}14(48.3 \%) \\
6(27.3 \%)\end{array}$ & $\begin{array}{l}15(51.7 \%) \\
16(72.7 \%)\end{array}$ & 0.128 & $\begin{array}{l}6(20.7 \%) \\
3(13.6 \%)\end{array}$ & $\begin{array}{l}23(79.3 \%) \\
19(86.4 \%)\end{array}$ & 0.714 & $\begin{array}{l}6(20.7 \%) \\
4(18.2 \%)\end{array}$ & $\begin{array}{l}23(79.3 \%) \\
18(81.8 \%)\end{array}$ & 1 & $\begin{array}{l}2(6.9 \%) \\
0\end{array}$ & $\begin{array}{l}27(93.1 \%) \\
22(100 \%)\end{array}$ & 0.500 \\
\hline
\end{tabular}

responses (38.4\%), which occurred after up to three courses for eleven of them. Fourteen patients (26.9\%) underwent macroscopically complete LM resections (R0-R1). Median progression-free survival (PFS) was 8.6 months (6.6-10.7) and median overall survival was 21.9 months (15.0-28.7), with ten 4-year survivors (19\%). Ninety-five polymorphisms were identified within the 207 reference SNP (rs) identification numbers tested (Supplementary Table S1), with 16 loci (7.7\%) in 10 out of 34 ADME genes (29.4\%) successfully passing the stringent filtering process, thus undergoing evaluation regarding relations to outcomes.

Association of VKORC1 polymorphisms with early response, objective response and overall survival. Two loci (rs9923231 and rs9934438) in VKORC1 were robustly associated with both early response and overall objective response, while SNPs in rs9923321 were also associated with overall survival (Figure 2). For rs9923231, $\mathrm{T} / \mathrm{T}(N=8)$ as compared to $\mathrm{C} / \mathrm{T}(N=21)$ had greatest chance of achieving both early response (50\% vs 5\%, $P=0.029$; Supplementary Table S2) and 5-year survival (46\% vs $0 \%, P=0.006$; Figure 2). Single-nucleotide polymorphisms in rs9923231 further displayed a non-statistically significant association with arterial thrombosis, while SNPs in rs7294 locus were associated with such adverse event. For rs9923231, arterial thrombosis was encountered in $77 \%$ of the $\mathrm{T} / \mathrm{T}$ patients as compared to $30 \%$ of the $\mathrm{C} / \mathrm{C}$ ones $(P=0.04)$. As a result, the odds ratios clearly revealed that the T/T genotypes of rs9923231 had more early responses, and more catheter thrombosis as well, and displayed a far better survival as compared to the $\mathrm{C} / \mathrm{T}$ genotyped patients (Figure 2). Single-nucleotide polymorphisms in CYP2C19 (rs12248560) and SLC15A2 (rs1243672) were also associated with early, but not objective response or survival (Supplementary Table S2).

$\mathrm{N}$-acetyltransferase 2 polymorphisms and conversion to resection. Two SNPs within the NAT2 gene (rs1801280 and rs179929) were associated to LM R0 + R1 resection, and further confirmed so, using LD analysis (Figure 3). For rs 1041983, the rate of LM resections was as low as $13 \%$ and $20 \%$ for the patients with $\mathrm{C} / \mathrm{C}$ and $\mathrm{T} / \mathrm{T}$, respectively, as compared to $50 \%$ for $\mathrm{C} / \mathrm{T}$ ( $P$ from exact Fischer $=0.024)$. For rs 1801280 , the LM resection rate ranged from $6.25 \%$ for the $\mathrm{C} / \mathrm{C}$ patients to $42.8 \%$ for the $\mathrm{T} / \mathrm{T}$ ones $(P=0.055)$. Univariate analyses indicated that an increased likelihood of achieving R0-R1 resection was significantly associated with both (a) clinical factors, including a male sex, an age $\leqslant 60$ years, a liver involvement $\leqslant 25 \%$, a number of metastases $\leqslant 10$, a largest metastasis diameter $\leqslant 53 \mathrm{~mm}$ and a single prior systemic chemotherapy protocol, and (b) NAT2 rs1801280 T/T. Multivariate logistic regression identified NAT2 (rs1801280) as the single independent prognostic factor of macroscopically complete LM 

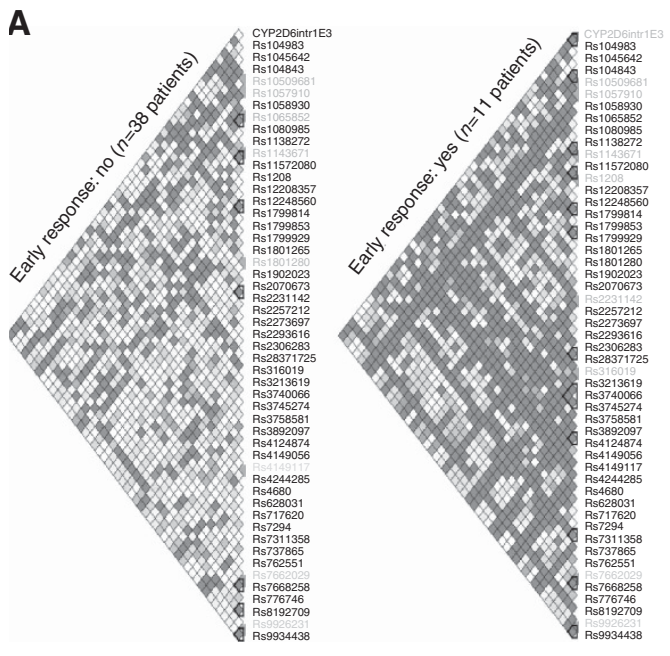

B

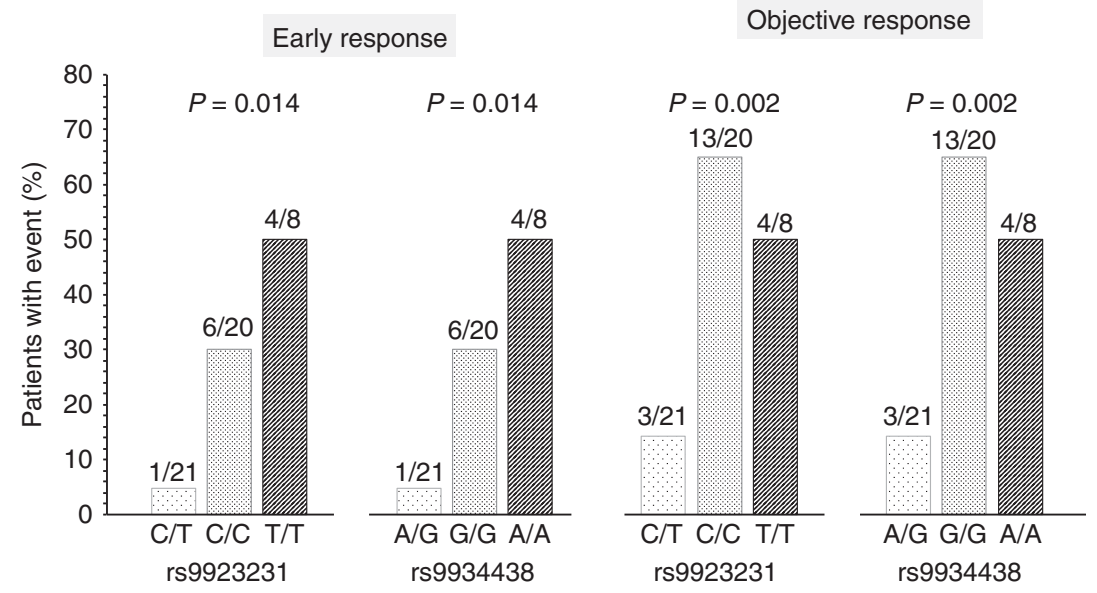

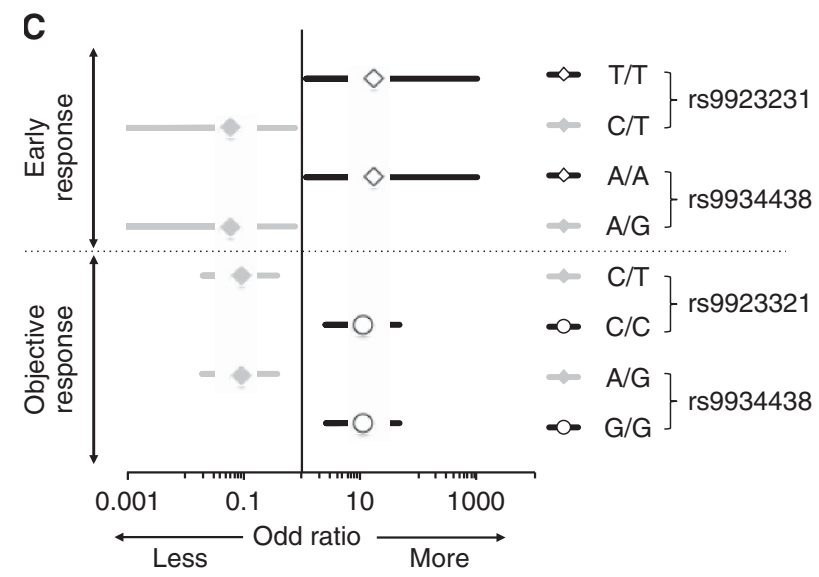

D

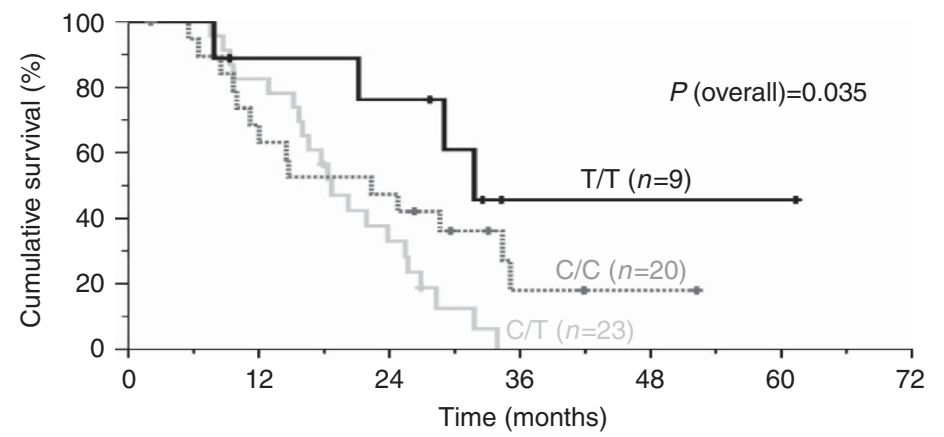

Figure 2. Associations between VKORC1 SNPs (rs9923231 and rs9934438) and efficacy or tolerability end points of i.v. Cet and triplet HAI protocol. (A) Results from LD analysis on whole study population stratified according to early tumour response. After filtration with HWE test, pairwise analysis was conducted to identify blocks of LD using Gabriel method. Blocks grouping SNPs are represented by geometric triangles in black. Singlenucleotide polymorphisms flagged in blue have a correlation coefficient $>0.8$ in the pairwise analysis. The more intense the red colour in each heatmap cell, the higher the correlation coefficient between two SNPs in the same group of patients. Note: this analysis revealed that SNPs' correlation with no distance limit was highest in the early response group (panel on the right) as compared to the non-early response group (panel on the left). The results suggest both least genetic heterogeneity in the early responders and adequate selection of SNPs for such analysis. (B) Column graphs describing the relations of VKORC1 SNPs with early and objective responses. Number of patients with response out of number of patients with corresponding genotype is indicated above each column. P-values are from Fischer exact. (C) Corresponding odds ratios. (D) Overall survival curves according to rs9923231 SNPs. P-value from log-rank test shown for overall comparison. Statistically significant differences in survival curves further documented between T/T (median, 31.8 months) and C/T (median, 18.7 months (15.0-22.3); intermediate median survival for C/C, 22.3 months (7.8-36.9). Note best efficacy for three end points in rs $9923231 \mathrm{~T} / \mathrm{T}$. A full colour version of this figure is available at the British Journal of Cancer journal online.

resection. The hazard ratio ( $\mathrm{T} / \mathrm{T}$ vs $\mathrm{C} / \mathrm{C})$ was 18.8 (95\% $\mathrm{CL}$, $1.8-209.4 ; P=0.017)$.

$A B C B 1$ polymorphisms and PFS. Single-nucleotide polymorphisms at both rs1045642 and rs2032582 in $A B C B 1$ were associated with statistically significant differences in PFS $(P=0.026$ and 0.035 , respectively; Figure 4). For rs2032582, median PFS ranged from 7.0 months for $\mathrm{G} / \mathrm{T}(N=23)$, as compared to 10.9 months for $\mathrm{T} / \mathrm{T}(N=7 ; P=0.036)$. Moreover, disease progression occurred in all G/T or G/G patients within the 30 months following OPTILIV inclusion, while no progression was encountered for $29 \%$ of the $\mathrm{T} / \mathrm{T}$ genotype. Multivariate analysis further revealed that $A B C B 1$ (rs2032582) genotype was an independent prognostic factor of PFS, jointly with sex, initial liver involvement and R0-R1 resection (Supplementary Table S3). Interestingly, the other $A B C B 1$ polymorphic SNP (rs1045642) was also associated with severe neutropenia. Thus, $75 \%$ of the $\mathrm{T} / \mathrm{T}$ patients experienced grade $3-$
4 neutropenia, as compared to $41.9 \%$ of the $\mathrm{C} / \mathrm{T}$ genotype and $9.1 \%$ of the $\mathrm{C} / \mathrm{C}$ one (Supplementary Table S2; Figure 5).

Single-nucleotide polymorphisms associated with main systemic toxicities. Statistically significant associations $(P<0.05)$ of SNPs with main toxicity outcomes were found for oxydo-reduction (CYP2E1 and HA thrombosis, CYP2C9 and diarrhea, and CYP2C19 and both diarrhea and fatigue), conjugation (UGT1A6 and diarrhea, and NAT2 and fatigue), and transport (ABCB1 or SLCOB3 and neutropenia, and SLC22A1 and diarrhea; Supplementary Table S2; Figure 5). Interestingly, $A B C B 1$ (rs1045642) was the single-gene polymorphism that was statistically associated with both severe toxicity (grade 3-4 neutropenia) and the plasma pharmacokinetics parameters we determined during the first protocol course (Cmax of oxaliplatin and cetuximab, and estimated AUC of cetuximab) in a subset of 11 of these 52 patients (Supplementary Table S4). 

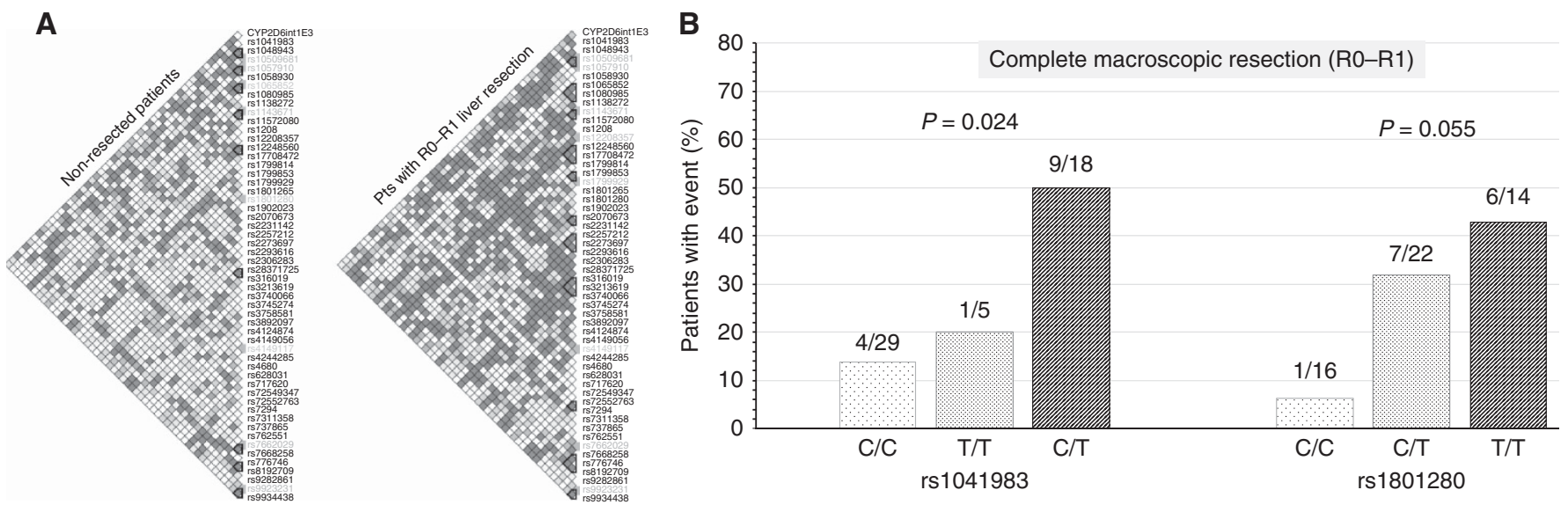

Figure 3. Associations between N-acetyltransferase 2 (NAT2) SNPs ( $r$ 1041983 and rs1801280) and macroscopically complete liver metastases resections (R0 + R1) following i.v. Cet and triplet HAI protocol. (A) Results from LD analysis on whole study population stratified according to R0 + R1, after application of Hardy-Weinberg method (see legend of Figure 2A). This display revealed both least genetic heterogeneity in the $\mathrm{R} 0+\mathrm{R} 1$ resection group (right panel), as compared to the non-resected patient group (left panel), and adequate selection of SNPs for such analysis. (B) Column graphs. Number of patients with R0-R1 resections out of number of patients with corresponding genotype is indicated above each column. P-values are from Fischer exact. A full colour version of this figure is available at the British Journal of Cancer journal online.
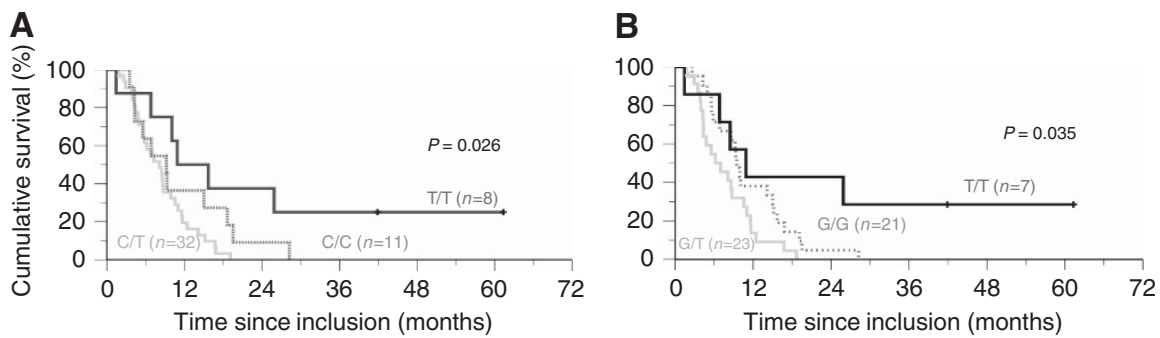

Figure 4. Progression-free survival curves according to $A B C B 1$ genotype at (A) rs1045642 (left) and (B) rs2032582. Number of patients per genotype in parentheses. $P$-value from log-rank test for each overall comparison. Statistically significant differences in survival curves were further documented for rs1045642 between $\mathrm{C} / \mathrm{T}$ (median, 8.1 months (95\% $\mathrm{CL}, 5.5-10.8)$ ) and $\mathrm{T} / \mathrm{T}$ (median, 10.9 months $(3.1-18.7)(P=0.015)$ ), and for rs2032582 between G/T (median, 7.0 months (3.2-10.8)) and both G/G (9.5 months (8.5-10.5) $(P=0.040)$ ) and T/T (10.9 months (4.7-17.1)).
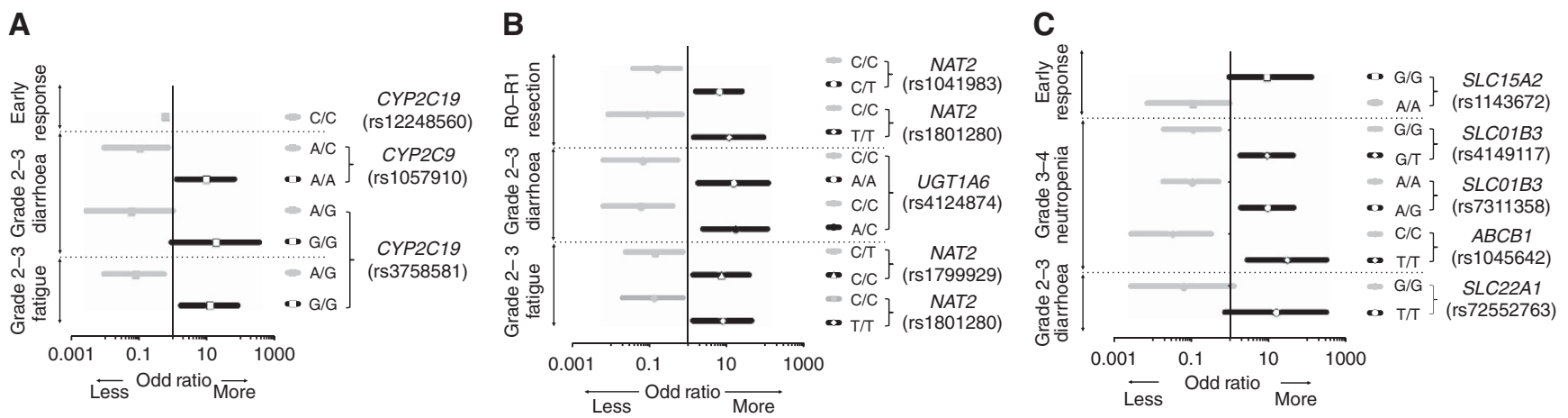

Figure 5. Relations between SNPs in selected drug metabolism genes and main OPTILIV treatment end points. Odds ratios and 95\% confidence limits for statistically significant associations with early response (upper rows) and main toxicities (lower rows). (A) Polymorphisms in phase 1 metabolism genes (CYP2C19 and CYP2C9) were associated with early response, diarrhoea and fatigue. (B) Phase II metabolism polymorphisms (NAT2 and UGT1A6) were related to (R0-R1) LM resection, diarrhoea and fatigue. (C) Phase 3 metabolism (SLC15A2, SLC01B3, SLC22A1 and $A B C B 1)$ were influential on early response, diarrhoea and neutropenia.

\section{DISCUSSION}

VKORC1 and NAT2 SNPs were identified for the first time, as critically influencing the main efficacy end points in patients receiving HAI chemotherapy jointly with i.v. cetuximab for liver metastases from KRAS wild-type colorectal cancer. The translational study population involved $81.2 \%$ of the patients registered from nine European cancer centres (Levi et al, 2016). Ninety-five SNPs were found out of the 207 regions in 34 drug metabolism genes, which had been selected in the Sequenom ADME panel. Sixteen SNPs in 10 genes displayed statistically significant relations with efficacy and/or toxicity, using stringent selection methodology, according to best practices for case/control association studies (Clarke et al, 2011). Preprocessing steps involved the removal of monomorphic alleles, samples with low 
detection efficiency and SNPs not passing minor allele frequency and HWE test thresholds. Linkage disequilibrium analysis and genotypic association test were then performed, and multiple testing correction tests were applied to select significant SNPs (Clarke et al, 2011; Robinson et al, 2011).

Single-nucleotide polymorphisms in the promoter region of VKORC1 (rs9923231) and its related intron (rs9934438) were significantly associated with both early and objective responses, while SNPs in the promoter region also correlated with overall survival. The promoter SNP-related differences were large, with respective early responders and 4-year survivors in $4.5 \%$ and $0 \%$ of the 21 heterozygous patients, as compared to $50 \%$ and $46 \%$ of the 8 homozygous $\mathrm{T} / \mathrm{T}$ patients. Intermediate rates were found for both end points in $\mathrm{C} / \mathrm{C}$ patients $(30 \%$ and $18 \%$, respectively). The VKORC1 gene, located on chromosome 16, encodes for an enzymatic protein responsible for both the reduction of vitamin $\mathrm{K}$ 2,3-epoxide to the activated form, and the $\gamma$-carboxylation of several coagulation factors. VKORC1 is the major pharmacodynamics target of warfarin anticoagulant therapy, with the determination of SNPs at rs9923231 and rs9934438 being recommended for warfarin dose adjustment (Wang et al, 2008; Owen et al, 2010). VKORC1-dependent $\gamma$-carboxylated proteins are also involved in bone formation (Johnson et al, 1991; Coutu et al, 2008), signal transduction (Nakano et al, 1997), antioxidation and lipid synthesis (Mukai et al, 1992; Fredericks et al, 2013), and androgen receptor regulation (Tew et al, 2017). The relevance of VKORC1 is currently emerging for prostate cancer, while recent reports support its role for cellular proliferation, reactive oxygen species production and apoptosis (Di et al, 2017).

Two SNPs in the NAT2 gene (rs1041983 and rs1801280) were associated with macroscopically complete liver metastases resection following effective triplet HAI and i.v. cetuximab. The NAT2 gene, located on chromosome $8 \mathrm{p} 22$, encodes the enzyme involved in the acetylation of xenobiotics. Polymorphisms in the NAT2 gene influence the slow $v s$ fast acetylator status of individuals (McDonagh et al, 2014). The combination of both SNP genotyping used here displayed similar sensitivity and specificity as the conventional 7-SNP genotyping of NAT2 for the determination of the acetylator phenotype (Selinski et al, 2011; Suarez-Kurtz et al, 2016). Here the SNP-related differences were large, with R0-R1 LM resections occurring in $50 \%$ of the heterozygous $\mathrm{C} / \mathrm{T}$ genotype as compared to $14.7 \%$ of the homozygous ones $(\mathrm{C} / \mathrm{C}$ or $\mathrm{T} / \mathrm{T})$. To the best of our knowledge, no relation has been reported as yet regarding VKORC1 or NAT2 SNPs and efficacy or toxicity outcomes in cancer patients. Thus, the OPTILIV protocol could represent a preferred treatment option for those patients with both initially non-resectable LM-CRC, and constitutive SNPs at VKORC1 rs9923231 T/T, at NAT2 rs1801280 T/T and rs1041983 C/T, and/or $A B C B 1$ rs1045642 T/T and rs20132582 T/T. Indeed, such 'optimal' association of SNPs was found in an OPTILIV patient apparently cured from 27 synchronous liver metastases, after a disease-free and treatment-free interval of 6.5 years (Figure 2 in Levi et al. 2016).

In contrast, SNPs in the other eight ADME genes have already been associated to various clinical end points in patients on chemotherapy. This was notably the case of $A B C B 1$, whose SNPs at rs1045642 and rs2032582 were here associated with PFS, while those at rs1045642 were also associated with severe neutropenia. This suggested an important role of constitutive SNPs at this latter gene locus for chemotherapy detoxification both in host and in cancer cells. The SNPs in ABCB1 have been associated with toxic events in patients receiving irinotecan-based chemotherapy or capecitabine (Cortejoso et al, 2013; Garcia-Gonzalez et al, 2015) while a prognostic effect of ABCB1 variant (rs2032582) was reported for the overall survival of patients receiving FOLFIRI for metastatic colorectal cancer (De Mattia et al, 2013). In our study, the patients with T/T genotype in rs104642 had both worst neutropenia and best PFS. The same genotype was further associated with highest oxaliplatin and cetuximab exposure in the subset of patients undergoing pharmacokinetics determinations, while receiving chronomodulated triplet HAI. Severe neutropenia on FOLFOX has been shown to be a reliable prognostic indicator of PFS and OS in colorectal cancer patients (Innominato et al, 2011; Kasi et al, 2016). In addition, SNPs in five other ADME genes (CYP2C9, CYP2E1, UGT1A6, SLC01B3 and SLC22A1) only related to toxicity, suggesting their potential relevance for SNP-guided optimisation of tolerability without efficacy impairment.

In summary, the current pharmacogenetic investigation was carried out in previously treated patients receiving triplet HAI and i.v. cetuximab for unresectable LM from KRAS WT within a European prospective trial. The results emphasised critical and consistent roles for SNPs in VKORC1 and NAT2, two genes whose relevance for outcomes in cancer patients had not been reported before. $A B C B 1$ polymorphism was further highlighted as a joint predictor of neutropenia and PFS. Although OPTILIV was a prospective and multicentric trial, and stringent criteria were used for reliably selecting the relevant SNPs, the current study involved a limited size population, hence requiring further confirmation. Indeed, polymorphisms in VKORC1, NAT2 and $A B C B 1$ could help better tailor an aggressive liver-targeted medico-surgical strategy for LM from colorectal cancer.

\section{ACKNOWLEDGEMENTS}

This study was supported by the Association Internationale pour la Recherche sur le Temps Biologique et la Chronothérapie (ARTBC International).

\section{CONFLICT OF INTEREST}

VB has consulted or advised for Merck Serono, Amgen, SanofiAventis, Bayer and Prestizia; has received honoraria from Amgen, Merck Serono, Bayer, Roche, Novartis and Daiichi Sankyo; has received travel grants from Amgen, Merck Serono, Sanofi and Bayer; has received research funding from Merck Serono. JT has received honoraria from Merck, Amgen, Roche, Celgene, Sanofi, Lilly, Baxalta and Sirtex. RG has received travel grants Roche, Novartis, Ipsen, Sanofi and Lilly. RA has consulted or advised for Merck and Amgen; has received honoraria from Amgen, Merck, Sanofi and Astellas; and has received travel grants from Amgen, Merck, Sanofi and Astellas. MD has consulted or advised for Roche, Merck Serono, Amgen, Bohringer, Servier and Celgene; has received honoraria from Merck Serono, Roche, Amgen, Novartis, Lilly, Bayer, Ipsen, Servier and Celgene; has received travel grants from Roche, Merck Serono, Ipsen, Bayer and Celgene; and has received research funding from Merck Serono, Pfizer and Roche. His wife is Head of Business Unit Oncology of Sandoz. GM has consulted or advised for Merck, Pierre Fabre and Onxeo; has received honoraria from Merck, Roche, BMS, Novartis, Amgen and Pierre Fabre. The remaining authors declare no conflict of interest.

\section{AUTHOR CONTRIBUTIONS}

FL, AK, PI, MB, GM and AL designed the study; all co-authors collected the data; FL, AK, PI, CD and AL searched the literature; FL, AK, RS and CD analysed and interpreted the data; all coauthors were involved in the drafting or reviewing of report and approval of submitted manuscript. 


\section{REFERENCES}

Adam R, Delvart V, Pascal G, Valeanu A, Castaing D, Azoulay D, Giacchetti S, Paule B, Kunstlinger F, Ghemard O, Levi F, Bismuth H (2004) Rescue surgery for unresectable colorectal liver metastases downstaged by chemotherapy: a model to predict long-term survival. Ann Surg 240(4): 644-657; discussion 657-658.

Bismuth H, Adam R, Levi F, Farabos C, Waechter F, Castaing D, Majno P, Engerran L (1996) Resection of nonresectable liver metastases from colorectal cancer after neoadjuvant chemotherapy. Ann Surg 224(4): 509-520; discussion 520-522.

Bouchahda M, Boige V, Smith D, Karaboue A, Ducreux M, Hebbar M, Lepere C, Focan C, Guimbaud R, Innominato P, Awad S, Carvalho C, Tumolo S, Truant S, De Baere T, Castaing D, Rougier P, Morere JF, Taieb J, Adam R, Levi F. International A (2016) Early tumour response as a survival predictor in previously-treated patients receiving triplet hepatic artery infusion and intravenous cetuximab for unresectable liver metastases from wild-type KRAS colorectal cancer. Eur J Cancer 68: 163-172.

Bouchahda M, Levi F, Adam R, Rougier P (2011) Modern insights into hepatic arterial infusion for liver metastases from colorectal cancer. Eur J Cancer 47(18): 2681-2690.

Clarke GM, Anderson CA, Pettersson FH, Cardon LR, Morris AP, Zondervan KT (2011) Basic statistical analysis in genetic case-control studies. Nat Protoc 6(2): 121-133.

Cortejoso L, Garcia MI, Garcia-Alfonso P, Gonzalez-Haba E, Escolar F, Sanjurjo M, Lopez-Fernandez LA (2013) Differential toxicity biomarkers for irinotecan- and oxaliplatin-containing chemotherapy in colorectal cancer. Cancer Chemother Pharmacol 71(6): 1463-1472.

Coutu DL, Wu JH, Monette A, Rivard GE, Blostein MD, Galipeau J (2008) Periostin, a member of a novel family of vitamin K-dependent proteins, is expressed by mesenchymal stromal cells. J Biol Chem 283(26): 17991-18001.

D'Angelica MI, Correa-Gallego C, Paty PB, Cercek A, Gewirtz AN, Chou JF, Capanu M, Kingham TP, Fong Y, DeMatteo RP, Allen PJ, Jarnagin WR, Kemeny N (2015) Phase II trial of hepatic artery infusional and systemic chemotherapy for patients with unresectable hepatic metastases from colorectal cancer: conversion to resection and long-term outcomes. Ann Surg 261(2): 353-360.

De Mattia E, Toffoli G, Polesel J, D’Andrea M, Corona G, Zagonel V, Buonadonna A, Dreussi E, Cecchin E (2013) Pharmacogenetics of ABC and SLC transporters in metastatic colorectal cancer patients receiving first-line FOLFIRI treatment. Pharmacogenet Genomics 23(10): 549-557.

Di W, Khan M, Gao Y, Cui J, Wang D, Qu M, Feng L, Maryam A, Gao H (2017) Vitamin K4 inhibits the proliferation and induces apoptosis of U2OS osteosarcoma cells via mitochondrial dysfunction. Mol Med Rep 15(1): 277-284

Falvella FS, Cheli S, Martinetti A, Mazzali C, Iacovelli R, Maggi C, Gariboldi M, Pierotti MA, Di Bartolomeo M, Sottotetti E, Mennitto R, Bossi I, de Braud F, Clementi E, Pietrantonio F (2015) DPD and UGT1A1 deficiency in colorectal cancer patients receiving triplet chemotherapy with fluoropyrimidines, oxaliplatin and irinotecan. Br J Clin Pharmacol 80(3): $581-588$.

Fredericks WJ, Sepulveda J, Lai P, Tomaszewski JE, Lin MF, McGarvey T, Rauscher 3rd FJ, Malkowicz SB (2013) The tumor suppressor TERE1 (UBIAD1) prenyltransferase regulates the elevated cholesterol phenotype in castration resistant prostate cancer by controlling a program of ligand dependent SXR target genes. Oncotarget 4(7): 1075-1092.

Gabriel SB, Schaffner SF, Nguyen H, Moore JM, Roy J, Blumenstiel B, Higgins J, DeFelice M, Lochner A, Faggart M, Liu-Cordero SN, Rotimi C, Adeyemo A, Cooper R, Ward R, Lander ES, Daly MJ, Altshuler D (2002) The structure of haplotype blocks in the human genome. Science 296(5576): 2225-2229.

Garcia-Gonzalez X, Cortejoso L, Garcia MI, Garcia-Alfonso P, Robles L, Gravalos C, Gonzalez-Haba E, Marta P, Sanjurjo M, Lopez-Fernandez LA (2015) Variants in CDA and ABCB1 are predictors of capecitabine-related adverse reactions in colorectal cancer. Oncotarget 6(8): 6422-6430.

Giacchetti S, Itzhaki M, Gruia G, Adam R, Zidani R, Kunstlinger F, Brienza S, Alafaci E, Bertheault-Cvitkovic F, Jasmin C, Reynes M, Bismuth H, Misset JL, Levi F (1999) Long-term survival of patients with unresectable colorectal cancer liver metastases following infusional chemotherapy with 5-fluorouracil, leucovorin, oxaliplatin and surgery. Ann Oncol 10(6): 663-669.
Hertz DL, Rae J (2015) Pharmacogenetics of cancer drugs. Annu Rev Med 66 : 65-81.

Innominato PF, Giacchetti S, Moreau T, Smaaland R, Focan C, Bjarnason GA, Garufi C, Iacobelli S, Tampellini M, Tumolo S, Carvalho C, Karaboue A, Levi F. Group AIC (2011) Prediction of survival by neutropenia according to delivery schedule of oxaliplatin-5-Fluorouracil-leucovorin for metastatic colorectal cancer in a randomized international trial (EORTC 05963). Chronobiol Int 28(7): 586-600.

Johnson TL, Sakaguchi AY, Lalley PA, Leach RJ (1991) Chromosomal assignment in mouse of matrix Gla protein and bone Gla protein genes. Genomics 11(3): 770-772.

Kasi PM, Kotani D, Cecchini M, Shitara K, Ohtsu A, Ramanathan RK, Hochster HS, Grothey A, Yoshino T (2016) Chemotherapy induced neutropenia at 1-month mark is a predictor of overall survival in patients receiving TAS-102 for refractory metastatic colorectal cancer: a cohort study. BMC Cancer 16: 467.

Kemeny NE, Niedzwiecki D, Hollis DR, Lenz HJ, Warren RS, Naughton MJ, Weeks JC, Sigurdson ER, Herndon 2nd JE, Zhang C, Mayer RJ (2006) Hepatic arterial infusion versus systemic therapy for hepatic metastases from colorectal cancer: a randomized trial of efficacy, quality of life, and molecular markers (CALGB 9481). J Clin Oncol 24(9): 1395-1403.

Levi F, Karaboue A, Etienne-Grimaldi MC, Paintaud G, Focan C, Innominato P, Bouchahda M, Milano G, Chatelut E (2017) Pharmacokinetics of irinotecan, oxaliplatin and 5-fluorouracil during hepatic artery chronomodulated infusion: a translational European OPTILIV study. Clin Pharmacokinet 56(2): 165-177.

Levi FA, Boige V, Hebbar M, Smith D, Lepere C, Focan C, Karaboue A, Guimbaud R, Carvalho C, Tumolo S, Innominato P, Ajavon Y, Truant S, Castaing D, De Baere T, Kunstlinger F, Bouchahda M, Afshar M, Rougier P, Adam R, Ducreux M. Association Internationale pour Recherche sur Temps Biologique et C (2016) Conversion to resection of liver metastases from colorectal cancer with hepatic artery infusion of combined chemotherapy and systemic cetuximab in multicenter trial OPTILIV. Ann Oncol 27(2): 267-274.

Maeda Y, Shinohara T, Nagatsu A, Futakawa N, Hamada T (2016) Long-term outcomes of conversion hepatectomy for initially unresectable colorectal liver metastases. Ann Surg Oncol 23(Suppl 2): S242-S248.

McDonagh EM, Boukouvala S, Aklillu E, Hein DW, Altman RB, Klein TE (2014) PharmGKB summary: very important pharmacogene information for N-acetyltransferase 2. Pharmacogenet Genomics 24(8): 409-425.

Milano G (2016) Highlight on DPYD gene polymorphisms and treatment by capecitabine (.). Scand J Clin Lab Invest Suppl 245: S30-S33.

Mukai K, Itoh S, Morimoto H (1992) Stopped-flow kinetic study of vitamin E regeneration reaction with biological hydroquinones (reduced forms of ubiquinone, vitamin $\mathrm{K}$, and tocopherolquinone) in solution. J Biol Chem 267(31): 22277-22281.

Nakano T, Kawamoto K, Kishino J, Nomura K, Higashino K, Arita H (1997) Requirement of gamma-carboxyglutamic acid residues for the biological activity of Gas6: contribution of endogenous Gas6 to the proliferation of vascular smooth muscle cells. Biochem J 323(Pt 2): 387-392.

Owen RP, Gong L, Sagreiya H, Klein TE, Altman RB (2010) VKORC1 pharmacogenomics summary. Pharmacogenet Genomics 20(10): 642-644.

Robinson JT, Thorvaldsdottir H, Winckler W, Guttman M, Lander ES, Getz G, Mesirov JP (2011) Integrative genomics viewer. Nat Biotechnol 29(1): 24-26.

Selinski S, Blaszkewicz M, Lehmann ML, Ovsiannikov D, Moormann O, Guballa C, Kress A, Truss MC, Gerullis H, Otto T, Barski D, Niegisch G, Albers P, Frees S, Brenner W, Thuroff JW, Angeli-Greaves M, Seidel T, Roth G, Dietrich H, Ebbinghaus R, Prager HM, Bolt HM, Falkenstein M, Zimmermann A, Klein T, Reckwitz T, Roemer HC, Lohlein D, Weistenhofer W, Schops W, Hassan Rizvi SA, Aslam M, Banfi G, Romics I, Steffens M, Ekici AB, Winterpacht A, Ickstadt K, Schwender H, Hengstler JG, Golka K (2011) Genotyping NAT2 with only two SNPs (rs1041983 and rs1801280) outperforms the tagging SNP rs1495741 and is equivalent to the conventional 7-SNP NAT2 genotype. Pharmacogenet Genomics 21(10): 673-678.

Suarez-Kurtz G, Fuchshuber-Moraes M, Struchiner CJ, Parra EJ (2016) Single nucleotide polymorphism coverage and inference of $\mathrm{N}$-acetyltransferase-2 acetylator phenotypes in wordwide population groups. Pharmacogenet Genomics 26(8): 363-369.

Tew BY, Hong TB, Otto-Duessel M, Elix C, Castro E, He M, Wu X, Pal SK, Kalkum M, Jones JO (2017) Vitamin K epoxide reductase regulation of androgen receptor activity. Oncotarget 8(8): 13818-13831. 
Wang D, Chen H, Momary KM, Cavallari LH, Johnson JA, Sadee W (2008) Regulatory polymorphism in vitamin $\mathrm{K}$ epoxide reductase complex subunit 1 (VKORC1) affects gene expression and warfarin dose requirement. Blood 112(4): 1013-1021.

Williams JA, Andersson T, Andersson TB, Blanchard R, Behm MO, Cohen N, Edeki T, Franc M, Hillgren KM, Johnson KJ, Katz DA, Milton MN, Murray BP, Polli JW, Ricci D, Shipley LA, Vangala S, Wrighton SA (2008) PhRMA white paper on ADME pharmacogenomics. J Clin Pharmacol 48(7): 849-889.
Yoo J, Lee Y, Kim Y, Rha SY, Kim Y (2008) SNPAnalyzer 2.0: a web-based integrated workbench for linkage disequilibrium analysis and association analysis. BMC Bioinformatics 9: 290.

This work is published under the standard license to publish agreement. After 12 months the work will become freely available and the license terms will switch to a Creative Commons AttributionNonCommercial-Share Alike 4.0 Unported License.

Supplementary Information accompanies this paper on British Journal of Cancer website (http://www.nature.com/bjc) 